\title{
ENEKuS - a key model for managing the transformation of the normalisation of the Basque language in the workplace
}

To cite this article: Inazio Marko \& Iñaki Pikabea (2013): ENEKuS - a key model for managing the transformation of the normalisation of the Basque language in the workplace. Journal of Multilingual and Multicultural Development, 34:2, 154-170

To link to this article: http://dx.doi.org/10.1080/01434632.2012.733009

Key words: model, intervention, transformation, organisations, language normalisation, workplace

Abstract: The aim of this study is to develop a reference model for intervention in the language processes applied to the transformation of language normalisation within organisations of a socio-economic nature. It is based on the case study of an experience carried out over 10 years within a trades' union confederation, and has pursued a strategy of a basically qualitative research carried out in three stages: 1) undertaking field work through application of action-research methodology, 2) reconstructing experiences following processes of systematisation and conceptualisation of the systematised data, applying methodologies for the Systematisation of Experiences and Grounded Theory, and 3) formulating a model for intervention, applying the Systems Approach methodology. Finally, we identified nine key ideas that make up the conceptual framework for the ENEKUS reference model, which is structured in nine 'action points ', each having an operating sub-model applicable in practice.

Basque, the Basque Country's own language, is in a position of inferiority. Numerous initiatives to promote and normalise its use in recent decades have come from different spheres of society and public bodies: public administration, education, media, leisure activities, cultural activities and, increasingly, the world of organisations and business (Azurmendi 2005; Azurmendi \& Mtz. De Luna 2006; Cenoz 2008; Gardner \& Aldekoa 2002).

Nowadays, there are a great number of work-related organisations and business companies which are incorporating the Basque language into their daily work, image and systems, using planned processes designed for this. The first organisations to do this started their work in this area in the 1990 's, on the initiative of numerous company managers and employees, with institutional aid from the Basque Government, special technical support from consultancy companies and encouragement from social movements and trade unions. Following their example, more and more organisations have started to do the same. Thus, according to the data of the Basque Government Department for Language Policy (Gobierno Vasco 2011), between 1997 and 2009 there were 285 companies that received subsidies for developing plans for the Basque language; in 2009 these firms employed a total of 24,900 workers; and the budget earmarked to this end for this past year was $2,710,000 €$.

Over these years there have been considerable advances in the planning and methodology of practical programmes to modify language use within organisations. Key techniques have been created, planning methodology developed, training organized and material published. But it is obvious that there are still many shortcomings and many areas (philosophical, methodological, technical and social) that require further development. 
In the opinion of the author of this study, a significant shortcoming becomes apparent when starting a transformation process for language normalisation in organisations. Beyond the evaluation systems developed for certification and the methodological models developed for the technical process of planning, there is a need for an overall reference model that takes many other human factors into account: knowledge, culture and other aspects related to the approach to and management of the transformation of this process for language normalisation in all its complexity.

This research aims to take a new step towards solving these shortcomings which the work done so far has revealed. With this concern and interest, the first objective of our research is to define exactly which areas need to be taken into account. This has led us to define the initial question for structuring the approach of the research: which factors and/or elements should be taken into account in interventions applied to the transformation of language normalisation in organisations, and given the establishment of a reference model for intervention?

The second objective is to create a reference model for managing language normalisation within organisations. We aimed to create a systematised model to give structure to a series of cognitive theoretical references for the conceptualisation and practical methodological references for their application in the intervention.

Based on these targets, thus, structure is given to the general aim of the research - developing a reference model for managing language normalisation in organisations -, as well as to its concrete objectives: identifying the model's key sections, explaining their relevance, providing methodological tools and basic theoretical references, facilitating the modular adaptation of the model and identifying aspects for possible analysis for future research.

\section{Theoretical and conceptual context of the research}

In this research, two main areas are brought together: work organisations and language normalisation transformations; one linked with sociolinguistics and/or the development of languages in a society, and the other to the development of organisations.

This is why these two main areas have been considered - in order to determine the theoretical and conceptual focus of the research: 1) Firstly, a theoretical approximation was made of the language substitution and social revitalisation processes through providing the main theoretical points of view in order to explain them and through briefly explaining how these processes have taken place in the corporate social sphere in the Basque Country. 2) We then made a theoretical approximation for the development of organisations by defining the concept of organisation, by defining organisations as complex systems and by explaining the meaning and models of transformation in the organisations themselves. 
Figure 1. Theoretical and conceptual position of the research

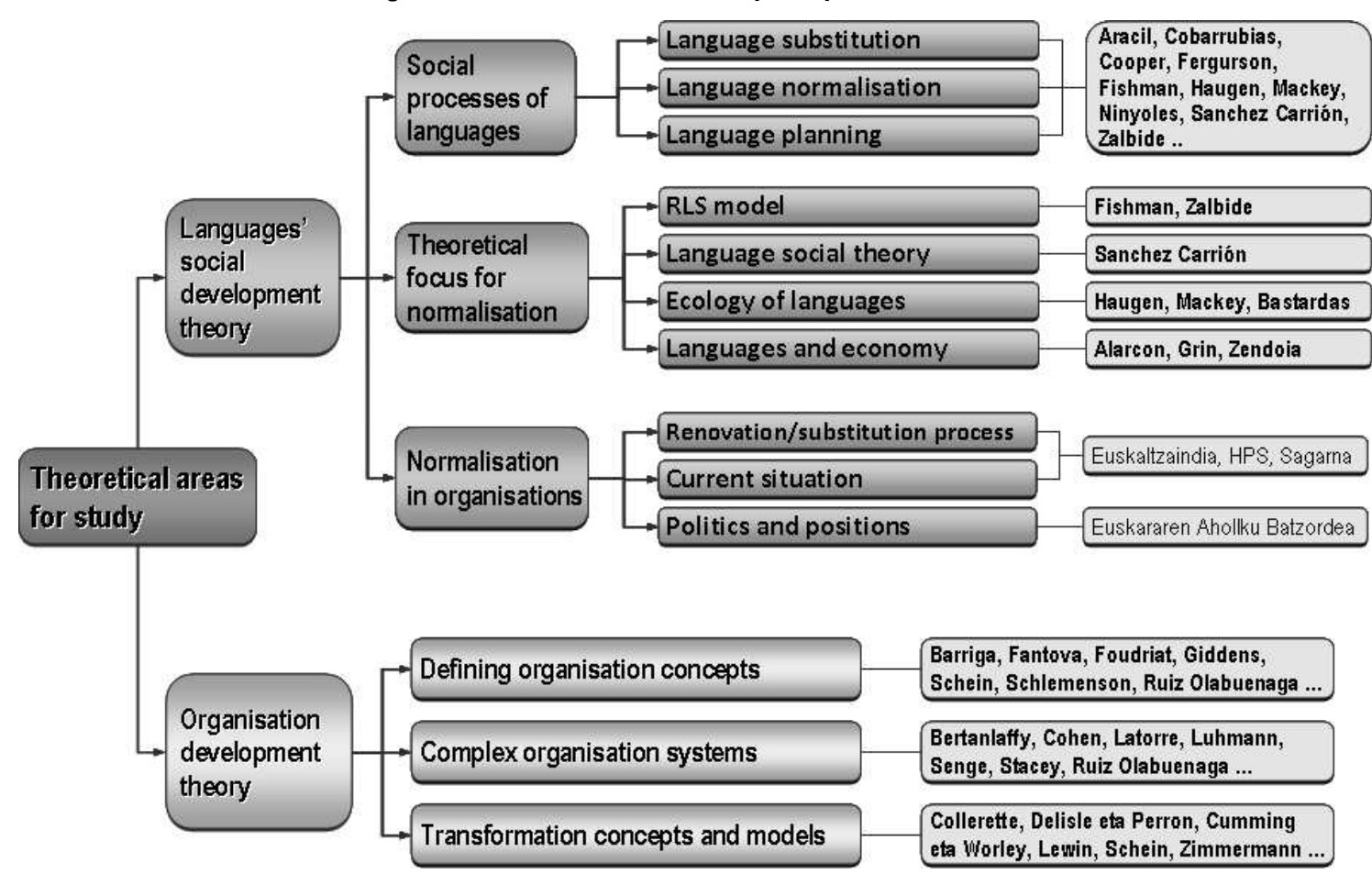

We aimed to investigate the concepts, points of view, data and authors related to the theory of the social development of languages in order to understand the position of the research subject in terms of language intervention in the area of sociolinguistics.

At the same time, we aimed to explain the complex systems that make up organisations as well as their importance in order to understand organisations as a system and to understand that considering transformation in language normalisation actually means considering transformation, not in the language itself (Marko 2008), but in the complex systems and subsystems within organisations (personnel, processes, structures, participation, relations, culture, etc.) In other words, we aimed to understand the difficulty of effecting and managing transformations within that complexity.

\section{Methodology of the research}

The objective of the research was to develop and propose a transformation model for the normalisation of the Basque language in the workplace and in organisations based on a review of an experience carried out within a labour (trades') union confederation. This was research with the practical goal of transformation: language normalisation, transformation, planned intervention, organising knowledge and similar key words describing concepts which are relevant to this study. In this sense, the essence of the research can be understood as a social phenomenon related to practical experience. That being so, and after research was undertaken using the interpretation of the subjects involved within the context where this phenomenon took place, and with the aim of encouraging the transformation, we based the perspective of the research on two main premises: 
- A PRAXEOLOGICAL one: our aim was to develop knowledge based on praxis, starting with practical cases, using a process of systematic reflection, with consequences for the processes of transformation. The lead researcher himself and other people involved in the study took part in this process.

- A CONSTRUCTIVIST one: the researchers and others involved analysed the reality, the intervention process and the results by interpreting this reality and by building new constructs in the systems of intervention.

Following on from these two approaches, the focus of our study can be positioned, on one hand, in a critical paradigm (Erlandson \& Harris 1993), following the action-research methodological strategy which applies quantitative and/or qualitative techniques for the gathering and analysis of data. On the other hand, a paradigm of the research can be positioned in the area of constructivism and this follows a methodological strategy of qualitative analysis based on the data and the systematisation of the action-research process.

In this sense, the research design was approached from the perspective of an emerging one, i.e. of a methodological process such as that described by Ferrero: "The fundamental characteristic of the emerging design is that it is not entirely established before the start of the study. It emerges as data is collected, the preliminary analysis is carried out and the context is described in a more complete manner» (Ferrero, 2003: 352).

The study was carried out in three phases: 1) the implementation of the initiative, 2) the reconstruction of the initiative 3) the preparation of the formal model applicable to new initiatives. Throughout these phases, we developed four analysis processes, staggered one after another. In the first phase, the field work of intervention was carried out. In the second phase, the experience undertaken was systematised and, based on this systematisation, theoretical conceptualisation was carried out. Finally, in the third phase, modelling was carried out in order to design a formal model of intervention based on theoretical conceptualisation. Each process of analysis was developed using the appropriate methodology:

- Field work: developed using action-research methodology;

- Systematisation: we used the methodology for the systematisation of experiences of social intervention;

- Theoretical conceptualisation: a methodological Grounded Theory model was followed;

- Modelling: finally, a systems approach was used.

Each of those methods was put into practice using many techniques for gathering data and for specific research. The following figure shows the main components in the completed methodological research programme carried out. 
Figure 2. Components of the methodological process of the research

\begin{tabular}{|c|c|c|c|c|}
\hline Phases & Analysis process & Methodology & \multicolumn{2}{|c|}{ Techniques } \\
\hline $\begin{array}{c}\text { Action } \\
\text { (intervention) }\end{array}$ & d & Action-Research & $\begin{array}{l}\text { - Interviews } \\
\text { - Marking scales } \\
\text { Questionnaire } \\
\text { Group discussions } \\
\text { - Evalaution sheets } \\
\text { - Measurement } \\
\text { observations }\end{array}$ & $\begin{array}{l}\text { - Registers } \\
\text { Sell-evaluation } \\
\text { - Focus groups } \\
\text { - Data cross- } \\
\text { checking } \\
\text { - Group debates } \\
\text { - Follow-up surveys }\end{array}$ \\
\hline \multirow{2}{*}{$\begin{array}{l}\text { Reconstruction } \\
\text { of the action }\end{array}$} & & $\begin{array}{l}\text { Systematisation } \\
\text { of Experiences }\end{array}$ & $\begin{array}{l}\text { - Systemization axis } \\
\text { - Document } \\
\text { organization } \\
\text { - Time line }\end{array}$ & $\begin{array}{l}\cdot \text { Constructive } \\
\text { narrative } \\
\text { Systemisation } \\
\text { process map }\end{array}$ \\
\hline & Onceptua & $\begin{array}{l}\text { Grounded } \\
\text { Theory }\end{array}$ & $\begin{array}{l}\text { - Open coding } \\
\text { - Categorization } \\
\text { - Code diagram } \\
\text { - Code paradigm }\end{array}$ & $\begin{array}{l}\text { Selective coding } \\
\text { Continual } \\
\text { comparison } \\
\text { - Theoretical scheme }\end{array}$ \\
\hline $\begin{array}{c}\text { Formulating an } \\
\text { action model }\end{array}$ & $\mathrm{N}$ & System Focus & \multicolumn{2}{|c|}{$\begin{array}{l}\text { - Theoretical scheme comparison } \\
\text { - Technical design development }\end{array}$} \\
\hline
\end{tabular}

The first phase was the stage of the experience involving field work research. This experience was carried out with the LAB trades' union confederation ${ }^{1}$. It took part in the process of the language normalisation of the Basque language between 1998 and 2008. The process of intervention was carried out using participants' action-research methodology (Katambwe 2005; Kemmis \& McTaggart 1988; Lewin 1946; Perez Serrano 1990), followed by the initiative-research-initiative cycle.

The second phase was that of the narrative and analytical reconstruction of the experience developed in the field work within the trades' union confederation. Two processes were carried out during this phase: systematisation of the results of the completed experiences and theoretical conceptualisation based on systematisation.

By using the process of systematisation (Alboan 2004; Borjas 2003; Jara 1994; Martinic 1999; Nina 2006), the results obtained in the first phase of the intervention were taken into account, the completed phases and steps of the study itself were organised, structure was given to analysis and detailed, structured and systemised explanations were given for the experience. In other words, the experience became a consistent discourse. But this consistent discourse was not just a description; on the contrary, it was aimed at answering the key question posed by the central premise of the same systematisation and, thereby, provided elements of information and analysis in reference to the research question. The structure of the discourse also took into account the practical limitations and made full use of the circular model derived from the action-research methodology applied to the process of intervention. Consequently, four temporary cycles or time phases were defined during the experience.

On the other hand, the objective of the theoretical conceptualisation was to create a theoretical outline to answer the key question arising from objectives of the research, basing

LAB (Langile Abertzaleen Batzordeak) is a trades' union confederation made up of trades' union workers who define themselves as a working class union, which is Basque-speaking and in favour of independence for the Basque Country. It was formed 30 years ago and has around 35,000 members and 200 staff members. The trade union has representatives throughout the Basque Country and offices in five provincial capitals, in all the main local towns and in many villages. 
itself on the results obtained during the process of systematisation; the Grounded Theory (Glasser \& Strauss 1967; Guillemette 2006; Strauss \& Corbin 1998; Sénéchal, 2008; Trinidad, Carrero \& Soriano 2006) methodological model being used to that end. The analysis of conceptualisation was carried out following the same circular model as defined in the process of practical systematisation. Systematisation and conceptualisation were incorporated one after the other: the first cycle's systematisation followed by its conceptualisation, the second cycle's systematisation by its conceptualisation, and so on. Thus, the four cycles were completed.

Lastly, the third phase, based on the theory of conceptualisation, was the phase of modelling and formulating a formal key model for implementing the transformation processes for language normalisation within organisations. The systems approach was used for that modelling (Collerette \& Delisle 1982).

\section{Reconstructing a practical case}

The preparatory work for this practical case provided a basis for the aim of this research and, as we have previously said, was carried out with the LAB trades' union confederation. It was undertaken between October, 1998 and June, 2008 and based on the EusLab Project (strategic planning for the normalisation of Basque in the trades' union confederation).

The analysis process for innovation, as already explained, was structured around two central premises: the systemisation premise and the conceptualisation one. These premises of analysis were carried out in four stages, each stage consisting of a complete cycle of systematisation and conceptualisation.

Figure 3. The stages of analysis for reconstructing a practical case

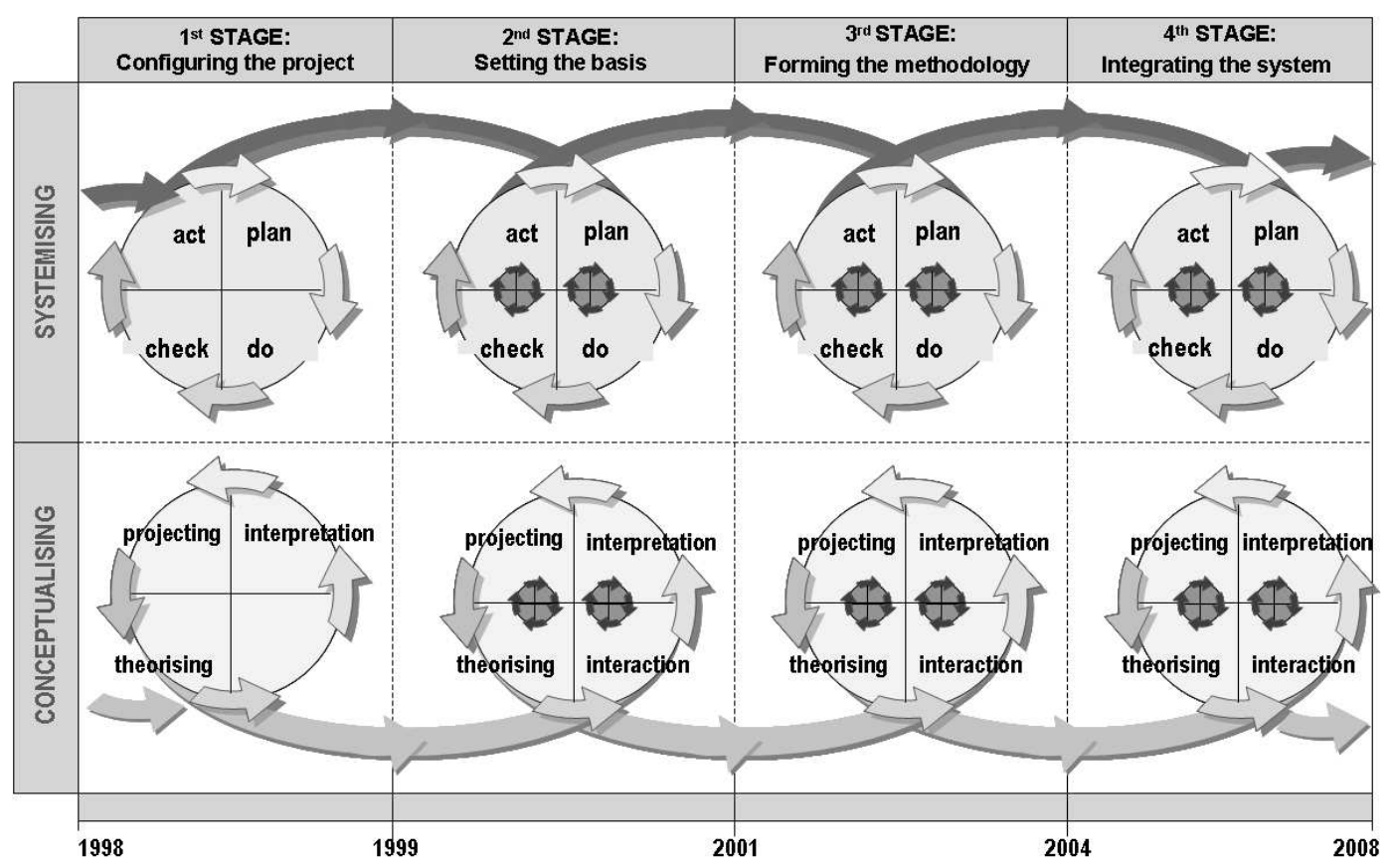

The time line below the scheme indicates the time limits of the stages. These limits, however, are defined by certain specific and important facts which determined the intervention cycles over the course of time. Following the methodological focus of the research, the 
systematisation cycle of each phase was applied first and the conceptualisation cycle applied later.

With all these factors incorporated, the methodological scheme or procedure guiding the reconstruction of a practical case was completed. Given this procedure, the main events of the experience, significant data of the processes and results thereof and the interpretations of those involved, were collected and systematised and, basing the analysis on such a systemisation, a theoretical conceptualisation aimed at providing an answer to the key questions arising from the objectives of the study was drawn up.

The results of this process of analysis formed the theoretical schema emerging and taking shape at the end of each cycle and, once completely drawn up, this defined the main factors to be taken into account and which, based on the results of this analysis, had to be incorporated when constructing a reference model for intervention in language normalisation.

\section{The proposed model: $E N E K u S$}

The ENEKuS model proposes a universal and systematic key framework in order to structure, systemise and optimise the process for managing intervention in the processes of change in the language normalisation for Basque in the workplace.

This model's main objectives are to:

- gather the necessary factors and/or key stages for planning and managing a process for language normalisation in organisations into a model of reference

- explain the importance and the objective of these aspects or stages of the model

- provide basic theoretical references which may be useful for future conceptual and methodological developments of these aspects or stages of the model

- provide guidance for drawing up and applying methodological tools that can be used in activities and courses of action in language normalisation

- facilitate systemisation for exchanging information about good practice in language normalisation projects

- facilitate systemisation for identifying ways and opportunities for learning and innovation.

In short, we aimed to construct a formal, logical, coherent and modulated model as a useful key framework for structuring language normalisation intervention projects.

The proposed ENEKuS model proposed in this paper was conceptualised based on the comparative analysis between two different theoretical schema linked to management: 1) the theoretical scheme arising from the conceptualisation of the experience carried out in the field for this research and 2) the theoretical scheme of the Basic Concepts for Excellence which support the EFQM model for excellence. 
So, the analysis of the relationships between the substantive theoretical schema arising from the specific experience implemented in the field work and the general one of principles defined for excellence in management, has given rise to a series of principles or a map of key ideas, making up the basic conceptualisation scheme on which the ENEKuS model is based.

Figure 4. Key ideas map for the ENEKuS model

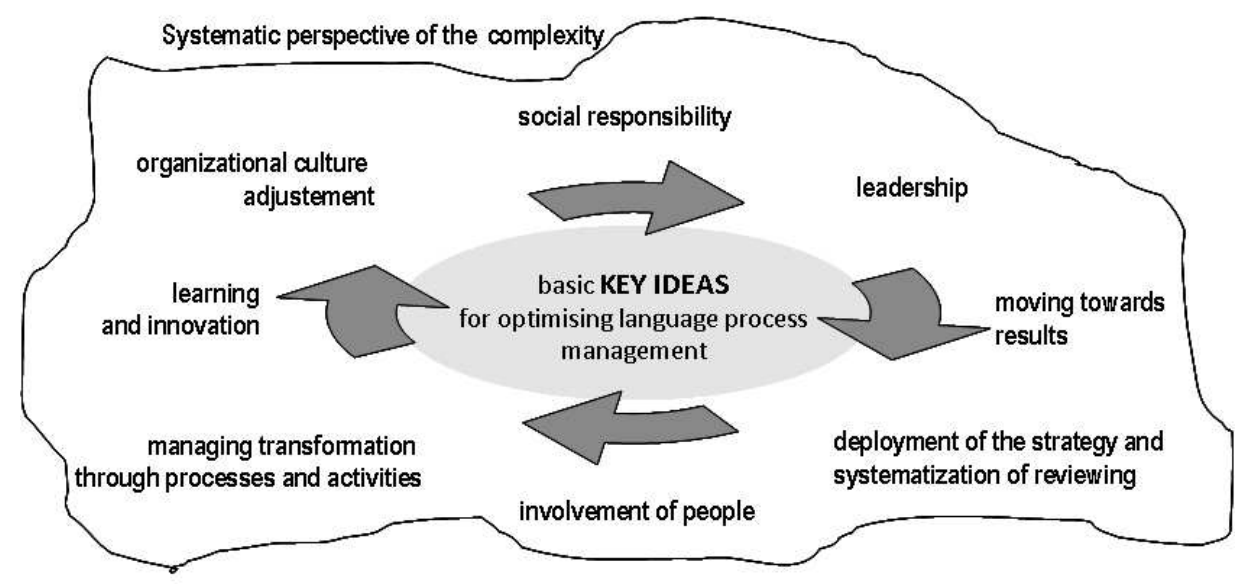

The basic key ideas map of the ENEKUS model explains the key ideas or essential concepts that should be taken into account to optimise the management of transformation in any particular language process inside an organisation, and how they should be interpreted in order to obtain optimum results. Taking these key ideas into account in this way, the management process for normalising the use of language in organisations will be optimum. The following were the key ideas for the ENEKuS model:

1. Key idea: systematic perspective of complexity. An optimised language normalisation process takes into account the diversity of the factors involved in the nature and context of the organisation to be transformed and, furthermore, it uses a systematic approach when dealing with and analysing the contextual reality.

2. Key idea: social responsibility. During a particular optimised language normalisation process, the organisation takes on social responsibility for the minoritised language and positively specifies this in its values and/or policies.

3. Key idea: leadership. In any optimised language normalisation process, the organisation's managers and management staff not only takes responsibility for the process, but also uses their institutional leadership to promote programmes and policies of language normalisation, making use of transformational leadership.

4. Key idea: moving towards results. A language normalisation process is based on data and is focused on obtaining results in line with the objectives set out by the strategies and policies for language normalisation. It also has a structured, integrated system for collecting and explaining data.

5. Key idea: deployment of the strategy and systematisation of reviewing. An optimised language normalisation process is methodologically formulated in order to specify strategic 
lines and objectives, to deploy those strategies operationally and to review and adjust operations and strategies.

6. Key idea: involvement of people. In an optimised language normalisation process, the persons in the organisation are involved in language normalisation management and implementation through the operational groups - they are given responsibilities for areas.

7. Key idea: managing transformation using processes and activities. An optimised language normalisation process manages language transformation through actions that affect ways of and structures for communication, and by establishing language criteria and making adjustments during the processes of organisation.

8. Key idea: learning and innovation. An optimised language normalisation process aims to find ways of innovation, improvement and obtaining results. That is why spaces and systems for learning and innovation have been incorporated into the intervention, establishing channels for carrying out methodological and communicative enhancements.

9. Key idea: organisational culture adaptation. In an optimised language normalisation process, the final result of language transformation is cultural transformation, that is to say, the cultural adaptation as a result of incorporating new ways of communication into the usual behaviour patterns and into the culture of the organisation.

Taking as a basis the fundamental concepts in this key ideas map, the ENEKuS key model was structured and represented as a diagram (Figure 5) of nine action-points, each divided into two inter-connected key axes. The action-points are based on the key ideas for optimising language normalisation processes and they should be taken into account when structuring transformational interventions. The axes are made up of a hard one and a soft one. The hard axis is technical and is connected to the technical and instrumental side of planning, interventions and measuring. The soft axis, on the other hand, is cultural and is connected to personal development, organisational style and the social aspects of cultural behaviour.

Figure 5. Structure graph for the ENEKuS model

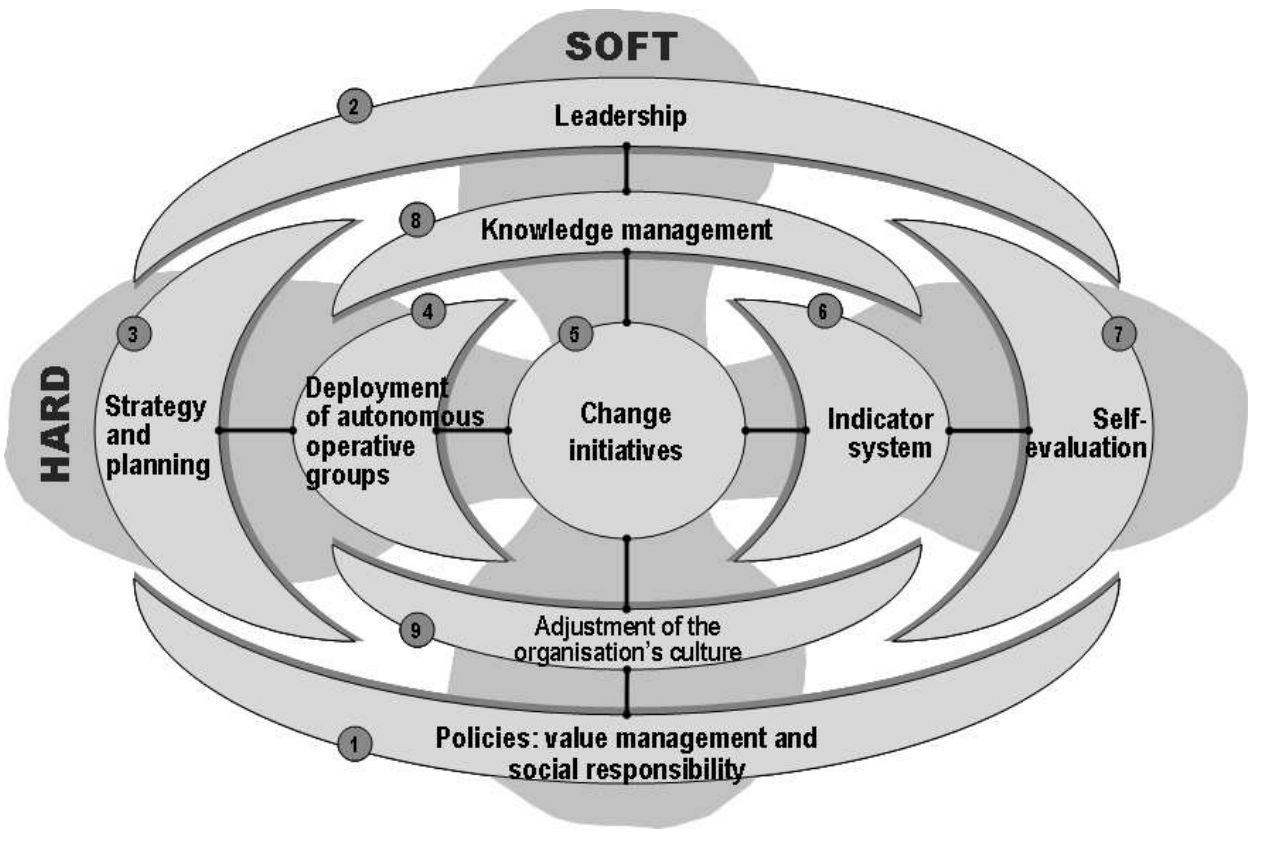


Thus, the interpretation of this ENEKuS model of reference, as shown in the figure above is as follows:

The organisation takes charge of the social responsibility for their own minoritised language (Basque in this case) and builds leadership for promoting language normalisation strategies and planning. These policies and strategies are deployed through independent operational groups which use a methodology of ongoing improvements, channelling initiatives and actions for the organisation's transformation. The results of these actions for change are gathered and measured using a system of indicators and, by developing knowledge for innovation, they are adjusted to new needs. The transformations are carried out through the adaptation of cultural behaviour and structural adjustment inside the organisation and they are evaluated through self-evaluation which enables reviewing the overall system.

In the technical design of the model, each of the action-points had its own theoretical and methodological preparation. In other words, for the conceptualisation of the concrete aspect of each action-point, key theoretical references were provided and the authors, concepts, perspectives, main references and theoretical models for each subject were taken into account.

Also, practical references for the development of each action-point were provided. These key practices materialised in operational sub-models created and designed to develop methodological strategies for each action-point. Apart from the modelling itself, those submodels offer methodological sequences, technical tools and key practical examples, with the aim of modelling and making operational the methodological strategies that can be developed in a concrete action-point.

Thus, the model for the nine action-points explains, on one hand, the factors that will be taken into account by a system for language normalisation and, on the other hand, the strategies and systems that it will develop in connection with those factors, and as outlined in the following table:

Table 1. Combined table showing the basic definitions for all the action-points

\begin{tabular}{|c|c|c|}
\hline & \multicolumn{2}{|c|}{ A system for managing the language normalisation in organisations } \\
\hline & takes into account: & and has developed strategies and methodologies: \\
\hline$\frac{\text { Action-point } 1}{\text { Responsibility }}$ & $\begin{array}{l}\text { the importance of talking about responsibility } \\
\text { regarding a minoritised language in the } \\
\text { organisation's values }\end{array}$ & $\begin{array}{l}\text { defining these values, including a language normalisation } \\
\text { area in which the company/organisation can create positive } \\
\text { language policies for social responsibility }\end{array}$ \\
\hline$\frac{\text { Action-point } 2}{\text { Leadership }}$ & $\begin{array}{l}\text { the importance of constructing an active, } \\
\text { efficient leadership force to promote the } \\
\text { process }\end{array}$ & $\begin{array}{l}\text { in a formal sense, the organisation's management should } \\
\text { accept responsibility for and get involved in the practical } \\
\text { leadership of language normalisation as befits them as } \\
\text { institutional leaders and, in an informal sense, promote } \\
\text { shared and transformational leadership of people and places } \\
\text { in a pro-active manner }\end{array}$ \\
\hline$\frac{\text { Action-point } 3}{\text { Strategies }}$ & $\begin{array}{l}\text { the importance of applying strategic lines and } \\
\text { language area objectives based on the } \\
\text { organisation's policies and values }\end{array}$ & $\begin{array}{l}\text { leading and putting into practice general reflections and } \\
\text { strategic planning }\end{array}$ \\
\hline$\frac{\text { Action-point } 4}{\text { Groups }}$ & $\begin{array}{l}\text { the importance of strategic planning for } \\
\text { language normalisation through local } \\
\text { interventions and organising along with } \\
\text { workers, management and implementation of } \\
\text { interventions }\end{array}$ & $\begin{array}{l}\text { building independent operational groups which take charge of } \\
\text { putting into practice said strategy by using methodology for } \\
\text { constant improvement and team-work philosophy }\end{array}$ \\
\hline
\end{tabular}




\begin{tabular}{|c|c|c|}
\hline$\frac{\text { Action-point } 5}{\text { Initiatives }}$ & $\begin{array}{l}\text { the importance of activating transformational } \\
\text { initiatives which will be influential in } \\
\text { relationships and work processes included in } \\
\text { the annual project }\end{array}$ & $\begin{array}{l}\text { designing and applying innovative and appropriate initiatives } \\
\text { for transformation in terms of appropriate and innovative } \\
\text { procedures and behaviour in order to promote language } \\
\text { normalisation in the organisation's procedure-building work } \\
\text { processes and non-procedure building processes. }\end{array}$ \\
\hline$\frac{\text { Action-point } 6}{\text { Indicators }}$ & $\begin{array}{l}\text { the importance of having data that provides } \\
\text { important and objective information in a clear } \\
\text { manner with regard to the progress of the } \\
\text { project, its level of achievement and the } \\
\text { results of the actions of the language } \\
\text { normalisation process and the situation at any } \\
\text { given time }\end{array}$ & $\begin{array}{l}\text { constructing a structured indicator system as a basis for the } \\
\text { qualitative review and evaluation of the project, the process } \\
\text { and the starting-point for language normalisation, and } \\
\text { determining and applying the data gathering procedure. }\end{array}$ \\
\hline$\frac{\text { Action-point } 7}{\text { Self-evaluation }}$ & $\begin{array}{l}\text { the importance of developing a systematic } \\
\text { evaluation process based on decisions about } \\
\text { adjustments and about indicators leading to } \\
\text { decisions taken periodically in order to develop } \\
\text { and improve the project and the entire system. }\end{array}$ & $\begin{array}{l}\text { adapting and applying a self-evaluation methodology that } \\
\text { helps to structure and put into practice the evaluation process } \\
\text { for taking decisions on developing plans and the system } \\
\text { overall }\end{array}$ \\
\hline$\frac{\text { Action-point } 8}{\text { Knowledge }}$ & $\begin{array}{l}\text { the importance of increasing and incorporating } \\
\text { into the collective knowledge, skills } \\
\text { (communicative for the use of language and } \\
\text { technical for participation in interventions), } \\
\text { needed for the optimum development of the } \\
\text { language normalisation process }\end{array}$ & $\begin{array}{l}\text { building operational systems in order to increase, create, } \\
\text { share, apply and innovate knowledge needed for socialising } \\
\text { language normalisation skills and techniques in } \\
\text { communications }\end{array}$ \\
\hline$\frac{\text { Action-point } 9}{\text { Culture }}$ & $\begin{array}{l}\text { the importance of understanding knowledge } \\
\text { created and the changes due to the language } \\
\text { normalisation interventions as an overall } \\
\text { process of cultural adjustment inside the } \\
\text { organisation. }\end{array}$ & $\begin{array}{l}\text { Reinforcing the process of incorporation of new ways of } \\
\text { working and communicating with the idea of carrying out } \\
\text { language normalisation developed inside the organisation's } \\
\text { system, into habits and structures and, in general, into the } \\
\text { overall culture of the organisation. }\end{array}$ \\
\hline
\end{tabular}

The ENEKuS model aims to provide answers for the different and complex realities of organisations. This led us to proposing a key system for creating solutions adapted to many different situations, and for constructing and managing multiple practical interventions.

On the other hand, we should note that, even though we present the model as a scheme of consecutive steps, in order to make explanations easy and understandable, it is not a linear model. On the contrary, depending on the organisation's characteristics and situation, as well as on the stage of the change process, some action-points take on more importance than others. In other words, the action-points specially prepared at the start of the language normalisation process of transformation will differ from the ones prepared at the end of the process or, at least, they will not be prepared in equal depth.

So, this is one of the main characteristics of the ENEKuS model: it is a dynamic, modular model. And, as much as it is modular, it is also open. This means that, whoever uses this key model, depending on their own particular circumstances, conditions and needs, can focus on their intervention at a particular action-point, or at various action-points or on the complete system. At the same time, we should not forget that we are dealing with complex organisations made up of people and structures and we cannot ignore overall, systematic perspectives.

\section{Discussion and Conclusions}

The process of the construction of the ENEKuS model was based on the qualitative analysis of the data gathered from each one of the phases of the experience, in order to provide a response to the key question of the research, seeking to identify what the fundamental aspects or elements are to be taken into account in the language normalisation of 
organisations. In this analysis of the conceptual categorisation of the interpretations and projections that the participants of the project undertook for the process itself, a theoretical schema emerged which takes in the key elements linked with the target question of the research.

A clear trend can be seen in the aspects or elements that appear in the theoretical schema arising from the analysis at each one of the stages. Thus, the principal aspects for a reference model, and that emerge in the conceptual schema of the first stage, basically make reference to questions linked to the nature of the intervention. This has to be a structured process (with strategic vision, participation of persons, planning and systemisation), that develops language normalisation initiatives (enhancing skills, encouraging use and boosting communication), takes advantage of existing positive knowledge (such as the demand of people for organisation, commitment by leaders or the existence of norms) in order to face the obstacle factors of the process (negative attitudes or fears about change); that is to say, aspects closely linked to methodology, planning and drawing up of intervention actions.

Emerging in the conceptual schema at the second stage, apart from the previous ones, are novel aspects to be taken into account, such as the need for developing leadership behaviour (at the level of commitment by directors and the development of language leadership), the centrality given to persons in this process (through their training and through their participation in management nuclei with operational independence), and the importance of providing the process with a system of indicators for the monitoring thereof, i.e. apart from aspects of a more technical nature, such as planning indicators and monitoring, other, more relational, aspects appear or are strengthened.

In the restructured schema arising at the third stage, new aspects appear which make reference to elements at an organisational level, such as the idea of developing organisational values with respect to the topic of language normalisation (assuming social responsibility, definition of language policies and specifying language criteria within the organisation), or the need for the application of normalisation initiatives for language change to processes of working, i.e. the planning of intervention is extended and goes from focusing on persons to addressing organisational processes and policies.

Finally, in the final reformulation of the theoretical schema that arise at the fourth stage, the conceptual analysis of the experience takes on new aspects, taking into account that the distribution of the schema is reordered - such as the idea of intervention focused on the achievement of results (with a system of indicators, not only for monitoring, but also for specifying results' targets); the concept of the process of language of change in the organisation as an action within complex contexts, with all that this means; the importance of learning through experience and innovation; and the final need to consider the aspect of change in organisational culture as a guarantee of integration into the style of functioning and relationships' structure of the organisation itself, with regard to the changes undertaken in the process of intervention for language normalisation.

In summary, we can see a clear trend in the successive reformulations of the emerging theoretical schema and which explains how the intervention is understood by people involved in the experience, given that they go from taking on, above all, technical-type aspects in their primary formulations, to finally considering the importance, together with technicalmethodological aspects (hard), of other, intangible and relational (soft) series of aspects and, moreover, with a holistic vision of the question in hand. This has been a fundamental idea and 
which, in our research, has meant significant knowledge regarding the formulation of the ENEKuS model, in the sense that it has been given a progressive and overall vision, and it has been provided with a basis for the idea of the double structure - 'soft' and 'hard' - for the model.

Also, the data for the indicators obtained in the intervention experience have acted as field work for this research, in as much as they have shown positive results, corroborating the analysis carried out. Thus, and as an example, an indicator for an important result such as that of the oral use of the language in everyday workplace relations shows, as we can see from the graph below, a positive trend over the years.

Figure 6. Index of the oral use of Euskara in workplace relations

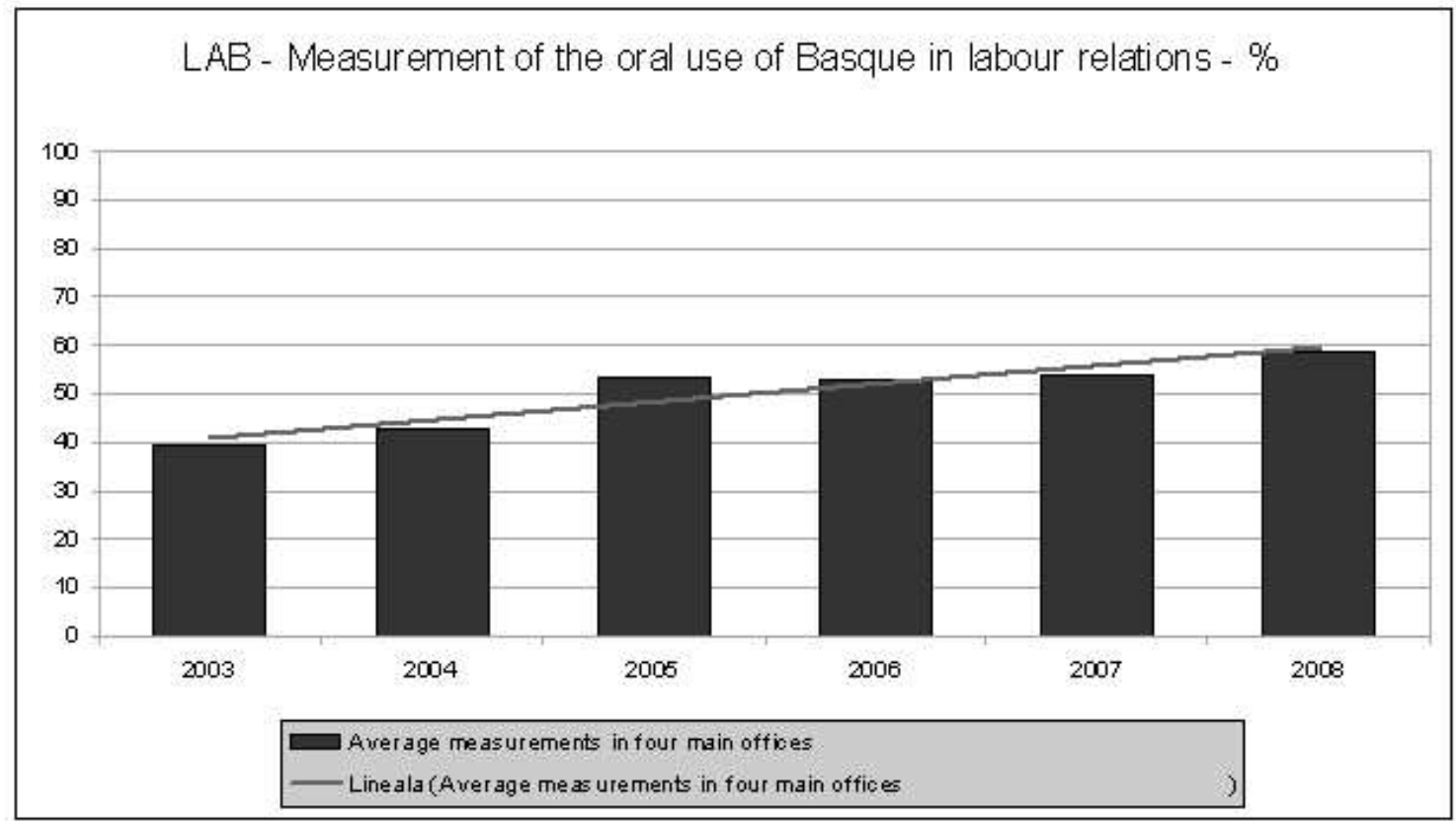

However, quite a clear conclusion can be drawn from the data obtained that the processes of language change are slow and are drawn out over time. In the same graph we can see that, together with the clearly positive trend which shows us the line of regression, the annual increases in the rate of use vary gradually. This is another important concept, implementing changes in established customs at a personal, relational or organisational structure level is a complex question which involves a lengthy process sustained over time.

In this sense, the most significant changes and those of greatest influence are those at the level of defining policies or strategic values for the application of criteria of functioning within the organisation. Also, as an example, we can see in the following graph, the date from the other important monitoring indicator which, in this case, reveals the percentage of interventions in Basque at meetings at an executive, decision-making level of the organisation. This organ gradually adopted a series of decisions at this level of stating language values and policies and which were applied to its own functioning (in questions of language criteria and language use, and at the level of the required language skills) and which were also reflected in the successive changes in the composition of personnel in the organisation in 2000 and 2004. The result is a very high rate of use of the Basque language at these working meetings, with a 
clearly positive tendency and with peaks that are manifestly better in the years in which the composition of the body was renewed.

Figure 7. Rate of interventions in Basque at National Committee meetings

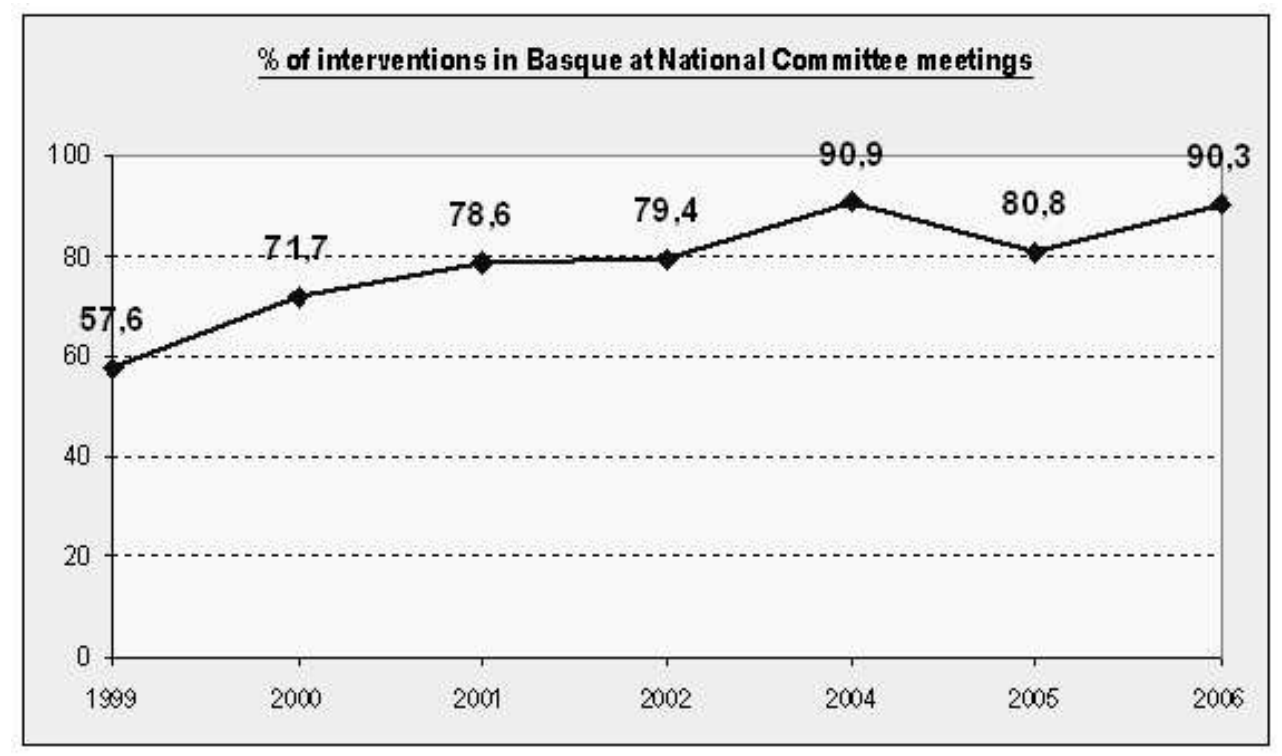

This is another important concept, given that decisions and changes made at the institutional level of policies, values and strategies provide great referentiality to the process of change, establishing ways of decision-taking and functioning which facilitate changes at other levels and enable this process to be integrated into the very culture and identity of the organisation.

Finally, we would like to underline the four main contributions of this study:

- The first contribution was the planning of the ENEKuS model itself. A theoretical and practical key model was designed to give an overall perspective of managing language normalisation processes and interventions in organisations and to offer conceptual and methodological references.

- The second contribution is the opportunity to make situational interpretations and direct language normalisation interventions according to situation interpretations. The modular nature of the model and its flexibility lends itself to adapting to interventions, customised to the situation and to each place and time.

- The third contribution was the different operational sub-models created and planned for the overall ENEKuS model. Many references, methodologies and tools are brought together in each of these sub-models which provide for a modular application of the model, to the extent that, depending on the needs of each case, they become references for optional and specific applications.

- The fourth contribution was the methodological model for carrying out the study. We can point out that, until now, Glaser and Strauss' Grounded Theory has been unknown in this area and that is why this work's methodological treatment can also be considered as 
an innovative contribution. The application of Grounded Theory and its methodology of continual comparison, based on the systematisation of the cyclical processes of research-action in interventions for the implementation of transformation in language normalisation, open new possibilities for developing methodology for the creation of theoretical models in applied research in this field.

The model presented in this study is an attempt to take into account the complexity of language normalisation and organisations and it is in no way a closed model. On the contrary, it is an open proposal, which we believe has provided new contributions in the area of accumulating knowledge in this field. It has also opened doors to new questions and shortcomings which have appeared and the need for new and greater knowledge about which we hope to find answers in the future. In this way, on concluding the study we saw new needs and/or possible lines of research for the subject in the future, of which the following were the most important:

- The ENEKuS model. Studying the suitability of the ENEKuS model and comparing the theoretical and methodological schemes used in organisations today in their language normalisation plans.

- Organisations' social responsibility. Investigating how to promote and study in-depth plans for social responsibility in basic language policies in organisations and how to socialise them.

- Leadership. The need to study in depth knowledge about applied leadership in the language normalisation process. How to study in-depth strategies for activating different leadership types which appear in the model. How to make the way for local leadership's self-image operational. Experimenting with operational strategies for executive leaders' transformational leadership. Putting experimental and comparative research into practice.

- Motivation. Studying motivational theory in connection with language normalisation leadership. Studying, in depth, research into the meaning of motivation, its importance and ways of making it operational.

- Operational groups. The need to study, in depth, the research of operational groups. Resolving complexities and paradoxes arising in practical cases: the importance and need for putting language normalisation change processes into practice and, at the same time, studying the difficulties that may arise in groups.

- Operational groups. Guiding comparative research between the groups (communication circles, practical groups, operational groups, etc.) created for the practical development of projects in organisations with language normalisation plans: ways of convincing groups, group characteristics, ways of working, duration, results, etc.

- Initiatives. Researching the value and influence of different initiatives for change (natural groups, ways of speaking, commitments, authority, involved persons, etc.). Comparing the influence and results of the starting-points for transformation, and which are based on protocolised behaviour and non-protocolised behaviour. Starting longitudinal and comparative research. 
- The organisation and contextual factors. Investigating the relationship between the organisation and its context and the direct influence of the context on the organisation. Comparing the use of Basque in organisations with all the results in their social context. What are the greatest limitations to language normalisation plans within an organisation? Can they be determined by the contextual situation? Or are the variables fairly independent?

- Culture. Research to identify the cultural factors and/or elements which express language normalisation in an organisation's culture. Studying an organisation's systems for perceiving the progress in incorporating language normalisation into an organisation's culture. Experimenting with planning for creating appropriate systems for cultural auditing.

Apart from the items we have dealt with in this paper, there are undoubtedly further questions and areas of study to be considered. But these are the reflections we have made during and after our research and the ones that are of most interest to us. Given the opportunity, they are the questions we would like to pursue in the future.

\section{Bibliography:}

Alboan (2004). La sistematización, una nueva mirada a nuestras prácticas. Guía para la sistematización de experiencias de transformación social. Bilbao: Alboan.

Azurmendi, M.J. (ed.) (2005). The case of basque: from the past toward the future. International journal of the sociology of language, 174 (Jul 2005), pp. 1-124. Berlin: Mouton de Gruyter.

Azurmendi, M.J. \& Mtz. De Luna, I. (ed.) (2006): The Case of Basque: Past, Present and Future. Andoain: Soziolinguistika Klusterra.

Borjas, B. (2003). Metodología para sistematizar prácticas educativas: Por las ciudades de Italo Calvino. Caracas: Federación Internacional de Fe y Alegría.

Erlandson, D. A., and Harris, E. L. (1993). Doing naturalistic inquiry. London: Sage Publications.

Cenoz, J. (ed.) (2008). Teaching through basque. Achievements and challenges. Clevedon: Multilingual Matters.

Collerette, P., and Delisle, G. (1982). Le Changement Planifie: Une Approche Pour Intervenir Dans Les Systemes Organisationnels. Québec: Editions Agence d'Arc.

Ferrero, G. (2003). De los proyectos de cooperación a los procesos de desarrollo. Unpublished doctoral thesis, Universidad Politecnica de Valencia, Valencia.

Gardner, N. \& Aldekoa, J. (2002). Turning knowledge of Basque into use: Normalization plans for schools. International Journal for Bilingual Education and Bilingualism, 5, 339-354..

Glaser, B., and Strauss, A. (1967). The discovery of grounded theory. Strategies for qualitative research. New York: Aldine.

Gobierno Vasco (2011, 12 de abril). EBPN: Indicadores de situación y evolución del euskara. Recuperado de http://www.euskara.euskadi.net/r59-738/es/contenidos/informacion/ argitalpenak/es_6092/investigaciones.html.

Guillemette, F. (2006). L'approche de la Grounded Theory; pour innover? Recherches Qualitatives, 26 (1), 3250. 
Jara, O. (1994). Para sistematizar experiencias: una propuesta teórica y práctica. Mexico: Alforja.

Jara, O. (2006). Sistematización de experiencias y corrientes innovadoras del pensamiento latinoamericano. Una aproximación histórica. La Piragua. Revista Latinoamericana de Educación y Política, 23, 7-16.

Katambwe, J. M. (2005). Recherche-action et consultation en communication des organisations: La production de savoirs sous double-contrainte. Recherches Qualitatives, Hors-Série - $N^{o}$ 1. Actes du colloque RECHERCHE QUALITATIVE ET PRODUCTION DE SAVOIRS, UQAM, 12 mai 2004, 61-72.

Kemmis, S. \& McTaggart, R. (1988). The action research planner. Victoria: Deakin University Press.

Lewin, K. (1946). Action research and minority problems. Journal of Social Issues, 2(4), 34-46.

Marko, J.I. (2008). EraLan ikerketaren marko teorikoa. Organizazio mailan hizkuntza-normalizaziorako interbentzioen marko teorikoa kontzeptualizatzeko oinarriak. [Theoretical framework of the EraLan research. Bases for the conceptualisation of a theoretical framework for intervention in language normalisation at an organisational level]. In J.I. Marko, eta O. Lujanbio, (Arg.), EraLan ikerketaproiektua: EPESA metodologia. Lan giroko hizkuntza erabileran eragiten duten aldagaietan oinarritua (17-28 orr.). Andoain: Soziolinguistika Klusterra.

Marko, J. (2010). ENEKuS Eredua, lan-munduko organizazioetan euskararen normalizaziorako eraldaketa kudeatzeko erreferentziazko eredua. [Management of changes for language normalisation in organisations: the ENEKuS model]. BAT - Soziolinguistika Aldizkaria, 2010 (3), 125-144.

Martinic, S. (1999). El objeto de la sistematización y sus relaciones con la evaluación y la sistematización. $L a$ Piragua. Revista Latinoamericana de Educación y Política, 16, 44-51.

Nina, A. (2006). Guía de Sistematización. El Salvador: GTZ.

Pérez Serrano, G. (1990). Investigación-acción. Aplicaciones al campo social y educativo. Madrid: Dykinson.

Sénéchal, Y. (2008): La théorisation des pratiques comme enjeu de la recherche participative. Recuperado de http://www.cacis.umontreal.ca/pdf/S\%C3\% A9n\%C3\%A9chalavril2008.pdf

Strauss, A. \& Corbin, J. (1998) Basics of Qualitative Research. Techniques and Procedures for Developing Grounded Theory (2nd edition). London: Sage Publications.

Trinidad, A., Carrero, V., \& Soriano, R. (2006). Teoría fundamentada "Grounded Theory". La construcción de la teoría a través del análisis interpretacional. Madrid: CIS. 